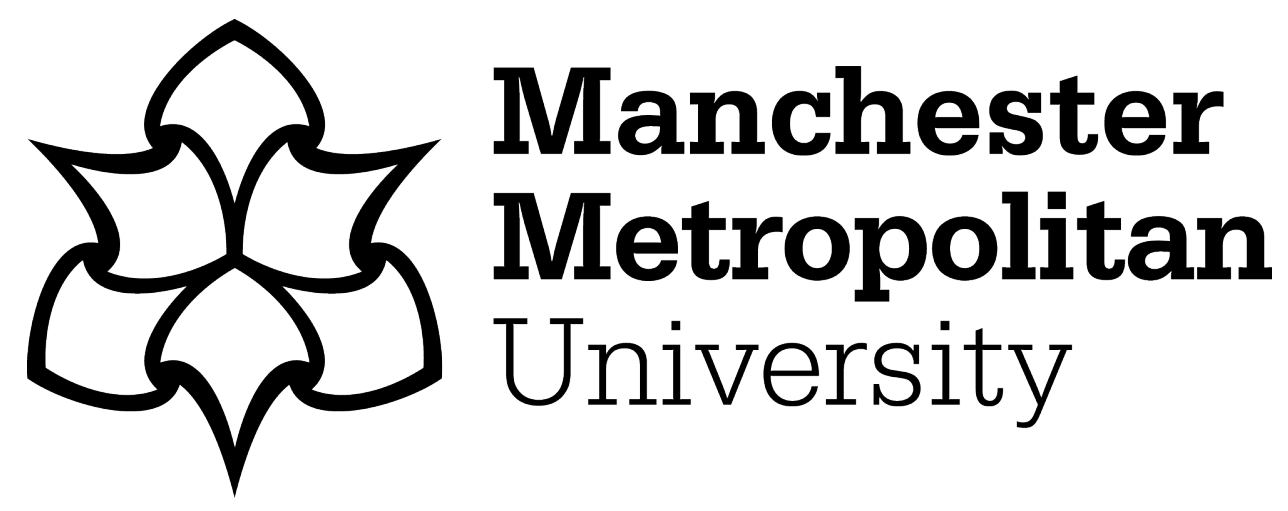

Han, DID, Tom Dieck, $M C$ and Jung, T ORCID logoORCID: https://orcid.org/0000-0002-8594-6641 (2019) Augmented Reality Smart Glasses (ARSG) visitor adoption in cultural tourism. Leisure Studies, 38 (5). pp. 618-633. ISSN 0261-4367

Downloaded from: https://e-space.mmu.ac.uk/623219/

Version: Accepted Version

Publisher: Taylor \& Francis

DOI: https://doi.org/10.1080/02614367.2019.1604790

Please cite the published version 


\title{
Augmented Reality Smart Glasses (ARSG) visitor adoption in cultural tourism
}

\author{
Dai-In Danny Han ${ }^{\mathrm{a}}$, M. Claudia Tom Dieck ${ }^{\mathrm{b}}$ and Timothy Jung ${ }^{\mathrm{b}}$

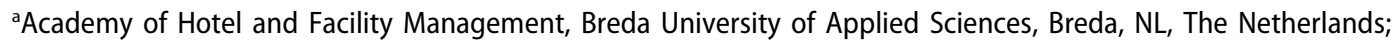 \\ bFaculty of Business \& Law, Manchester Metropolitan University, Righton Building, Manchester, UK
}

\begin{abstract}
A number of organizations in cultural tourism have started to explore the use of augmented reality (AR) to enhance visitor experience. While many studies have been conducted to identify adoption criteria of mobile AR applications, research exploring the adoption of augmented reality smart glasses (ARSG) is still limited. This paper contributes to the technology adoption literature by investigating attributes of visitor adoption of ARSG in cultural tourism. Twenty-eight interviews were conducted with visitors to a UK art gallery, where they experienced an ARSG application. Findings inform an ARSG adoption framework that integrates societal impact, perceived benefits, perceived attributes of innovation, and visitor resistance as the main themes of ARSG adoption in cultural tourism.
\end{abstract}

\section{Introduction}

Augmented reality (AR) has experienced a tremendous growth in research within academia and industry, with an aim to enhance tourism and leisure experience. The importance of technological innovations in the leisure industry was highlighted by Schultz and McKeown (2018, p. 223), who revealed that for 'leisure scholars to stay relevant in our current society, the topic of digital leisure spaces and cultures should become a central rather than periphery[sic] focus.' Recent success and understanding of AR can be linked to a wider use of smartphones, higher processing capabilities, and the consequent development of a variety of applications (Han, Jung, \& Tom Dieck, 2019). This development was further fueled by Pokémon Go, which was marketed as the first multiplayer AR game for mobile devices. People around the world suddenly started to engage in AR in their leisure time - in this case, chasing Pokémons around cities - and some studies found that the game contributes to an active lifestyle (Gabbiadini, Sagioglou, \& Greitemeyer, 2018). In recent years, extensive research has been conducted in the area of mobile AR in the leisure context (Kourouthanassis, Boletsis, Bardaki, \& Chasanidou, 2015; Layland, Stone, Mueller, \& Hodge, 2018); however, research on wearable AR is limited, despite the extensive investments and hardware development in augmented reality smart glasses (ARSG).

One leisure industry that is particularly affected by advancements in immersive technology is tourism and hospitality (Jung, Chung, \& Leue, 2015; Jung, Tom Dieck, Lee, \& Chung, 2016; Tom Dieck, Fountoulaki, \& Jung, 2018a). While previous studies (Han, Tom Dieck, \& Jung, 2017; Jung \& Tom Dieck, 2017; Jung, Tom Dieck, Moorhouse, \& Tom Dieck, 2017) suggested that such technologies enhance the tourist experience, actual use of ARSG in the leisure industry is still largely limited to usability demonstrations. Extensive research into technology adoption and diffusion has been conducted, revealing that the adoption of technology is a complex process that is influenced by three 
dimensions: individual differences, innovation characteristics, and the context of implementation (Straub, 2009). This means that in order to capture dimensions relevant to the specific technology, the visitor, and the implemented context, cognitive, emotional, and contextual concerns must be addressed when studying the adoption of innovative technologies such as ARSG in tourism.

While technology acceptance concerning mobile AR applications has been studied to explore cognitive and rational values (Amaro \& Duarte, 2015), research focusing on ARSG adoption behavior is scarce; one of the only studies on ARSG adoption was conducted by Rauschnabel and Ro (2016). The use of AR was found to particularly benefit cultural heritage tourism (Han et al., 2017; Tom Dieck \& Jung, 2018). Still, research into the adoption in this context is still limited.

According to Foley and McPherson (2000, p. 161), cultural heritage sites 'are shifting from a focus upon education alone towards an accommodation of leisure markets.' They argue that although the concept of 'recreation' is commonly associated with sports, museums and art galleries are still recreational institutions and are thus an important part of leisure activities. As such, a focus on entertainment and the use of latest technologies is becoming more important in enhancing the experience. In terms of the novelty factor of ARSG for enhancing the cultural tourism industry, a common belief in the field is that deeper knowledge is required of tourists' adoption of the technology, in order to guide future implementation of ARSG applications. Therefore, the aim of this paper is to explore and identify factors influencing ARSG adoption in cultural tourism, leaning on prior theories of technology adoption.

\section{Literature review}

\section{Augmented Reality Smart Glasses (ARSG) in cultural tourism}

Research on ARSG in cultural tourism has been limited (Leue, Jung, \& Tom Dieck, 2015; Tom Dieck, Jung, \& Han, 2016). The term 'ARSG' first emerged with Google Glass, a device capable of displaying digital information into the direct vision of the user through a glass prism. Due to the opportunity for people to experience cities, museums, and destinations hand-free, it was thought to be a good alternative to the traditional tour guide (Leue et al., 2015). Hein, Jodoin, Rauschnabel, and Ivens (2018) defined ARSG as a mobile computer in glasses form that is able to capture and interact with information from the real world and enhance it with virtual information, all in the user's field of vision.

Sultan (2015) recognized an interesting link between ARSG and the leisure industry, through ARSG's ability to influence peoples' leisure behavior by catching information anywhere and anytime. The potential to make information freely available is particularly expected to influence leisure activities such as sporting, museum and art gallery experiences, and shopping and entertainment. Leisure activities such as going to cinemas, concerts, and sporting events can easily be enhanced with ARSG by receiving additional information and offers. This not only affects the leisure experience itself but also influences memories of the event and behavioral intentions to share, return, or purchase (Tom Dieck, Jung, \& Rauschnabel, 2018b). However, in order to ensure that the leisure industry and related businesses benefit from ARSG applications, it is essential to understand how this new and innovative way of receiving information is adopted.

Ubiquitous AR, possibly in the form of ARSG, has been suggested as the ideal tool to guide tourists through unfamiliar environments (Rauschnabel \& Ro, 2016). On the one hand, the technology is able to support the effort of finding the way; on the other hand, it enables tourists to explore and discover unknown areas with context-relevant information. Particularly in terms of museums and art galleries, ARSG has been argued as potentially having the ability to replace traditional audio guides (Han, Jung, \& Gibson, 2013). ARSG are able to unobtrusively provide information hands-free to the visitor (Rauschnabel \& Ro, 2016), ultimately resulting in an undisturbed visitor experience.

Jhajharia et al. (2014) categorized the potential use of wearable technology in tourism into three types: a narrative clip to record life as it unfolds, a tourist diary to organize trips in multimedia 
recordings, and a Triposo travel belt to assist tourists' travel efforts in a more convenient, relevant, and efficient way. However, ARSG use is still limited in the tourism and leisure industries, and it struggles to make a breakthrough. The limited availability of applications and the cost associated with ARSG are certainly issues that affect mass adoption in the leisure industry (Tom Dieck et al., 2016); however, both obstacles are expected to be overcome in the near future. Nevertheless, the factors that contribute to technology adoption need to be determined, as well as what elements specifically related to ARSG will support adoption rates in the leisure industry.

\section{Adoption theories}

The theoretical background of this study is drawn from previous technology adoption theories. The Innovation Diffusion Theory (IDT) was one of the first approaches to explore acceptance and rejection of new innovations and has been used in other studies to study the adoption and diffusion of technological advancements in various industries. While Rogers (1996) showed that users tend to accept an innovation only if it seems adventurous to them, the positive perception of wearable devices is theorized to be based on enhanced connectivity and improved usability for a wide array of uses. Rogers' IDT (Rogers, 1996) revealed that relative advantage, compatibility, and complexity consistently impact the level of innovation, along with additional attributes outlined as observability and trialability.

Ajzen and Fishbein (1975) proposed the Theory of Reasoned Action (TRA), which is considered to be one of the first theories to be directly related to technological innovations. With TRA, it is assumed that behavioral intentions to adopt a technology are determined by attitudes and social influences. Ajzen (1985) further developed TRA and proposed the Theory of Planned Behavior (TPB) by adding perceived behavioral control into the equation. However, Mathieson (1991) studied TPB and revealed that its applicability lies more in the social aspects of behavior; consequently, the technology acceptance model (TAM) by Davis (1989) became the most widelyused theoretical foundation for studying technology adoption. According to Davis (1989), behavioral intentions to use a technology are driven by the perceived usefulness and ease of use of a system.

Later, variations of TAM progressed to models 2 and 3 (TAM2 and TAM3), or the United Theory of Acceptance and Use of Technology (UTAUT) (Venkatesh, Morris, Davis, \& Davis, 2003). Original theories were organization-focused; however, they have since been applied in a number of industries, including in tourism and leisure. Interestingly, these theories have much in common, and constructs are used interchangeably when studying the acceptance of technologies in various contexts. For instance, the biggest change UTAUT makes to previous theories is the inclusion of the expectancy and facilitating conditions constructs. Table 1 presents and compares the constructs identified in the theories discussed here.

Previous studies of technology adoption in tourism show that utilitarian and hedonic values have been studied extensively (Ajzen \& Fishbein, 1975; Davis, 1989; Rogers, 1996). However, it is

Table 1. Technology adoption theories.

\begin{tabular}{ll}
\hline Previous Theories & Constructs \\
\hline IDT (Rogers, 1996) & $\begin{array}{c}\text { relative advantage, compatibility, complexity, trialability, observability } \\
\text { TRA/ TPB (Ajzen \& Fishbein, } \\
\text { 1975; Ajzen, 1985) }\end{array}$ \\
$\begin{array}{c}\text { TAM (Davis, 1989) } \\
\text { control, intention to use, use behavior } \\
\text { TAM2/3 (Venkatesh \& Davis, } \\
\text { 2000; Venkatesh \& Bala, 2008) }\end{array}$ & $\begin{array}{r}\text { subjective norm, image, job relevance, output quality, result demonstrability, perceived } \\
\text { usefulness, perceived ease of use, intention to use, use behavior/ computer self- } \\
\text { efficacy, external control, computer anxiety, playfulness, usability, enjoyment }\end{array}$ \\
UTAUT (Venkatesh et al., 2003) & $\begin{array}{c}\text { performance expectancy, effort expectancy, social influence, facilitating conditions, } \\
\text { intention to use, use behavior }\end{array}$ \\
\hline
\end{tabular}


Table 2. Prior research on augmented reality smart glasses.

\begin{tabular}{|c|c|c|c|}
\hline Reference & Context & Sample and Methods & Previous findings \& contribution of this study \\
\hline $\begin{array}{l}\text { Chung, Lee, Kim, and Koo } \\
\text { (2018) }\end{array}$ & Cultural heritage sites & $\mathrm{N}=145, \mathrm{PLS}$ & $\begin{array}{l}\text { Expectation confirmation affects relative } \\
\text { advantage, aesthetics, and enjoyment. } \\
\text { Relative advantage and aesthetics affect } \\
\text { satisfaction, influencing attitude and } \\
\text { ultimately behavioural intentions }\end{array}$ \\
\hline $\begin{array}{l}\text { Jung, Lee, Chung, and } \\
\text { Tom Dieck (2018) }\end{array}$ & Cultural heritage sites & $\begin{array}{l}\mathrm{N}=119 \& 145, \text { SEM } \\
\text { Cross-cultural study }\end{array}$ & $\begin{array}{l}\text { Aesthetics, usefulness, ease of use, enjoyment } \\
\text { and social influence affect intentions. South } \\
\text { Korea stronger dependence on social } \\
\text { influence and enjoyment than Ireland. }\end{array}$ \\
\hline $\begin{array}{l}\text { Kalantari and } \\
\text { Rauschnabel (2018) }\end{array}$ & ARSG usage & Theoretical & $\begin{array}{l}\text { Benefits, risks, technology characteristics and } \\
\text { norms influence adoption. }\end{array}$ \\
\hline Rauschnabel (2018) & Students ARSG usage & $\mathrm{N}=228, \mathrm{SEM}$ & $\begin{array}{l}\text { Gratifications (utilitarian, hedonic, sensual, } \\
\text { social and symbolic) influence behavioural } \\
\text { intentions }\end{array}$ \\
\hline Tom Dieck et al. (2018b) & $\begin{array}{r}\text { Science festival } \\
\text { engagement }\end{array}$ & $\mathrm{N}=220, \mathrm{SEM}$ & $\begin{array}{l}\text { Experience economy affects satisfaction and } \\
\text { memory. Visitor engagement as dependent } \\
\text { variable. }\end{array}$ \\
\hline Our study & Cultural heritage & $\begin{array}{l}\text { Qualitative, Thematic } \\
\text { analysis, } 28 \\
\text { interviews }\end{array}$ & $\begin{array}{l}\text { Qualitatively proposing an ARSG adoption } \\
\text { model }\end{array}$ \\
\hline
\end{tabular}

evident that recent studies have largely focused on constructs found in TAM, and only a few studies have incorporated constructs from IDT or TRA. While this can be attributed to the oftenoverlapping nature of construct definitions, key constructs that accumulated in previous studies need to be explored. This will allow a more holistic approach when investigating the adoption of forthcoming technology (such as ARSG) and exploring whether additional and specific ARSGrelated constructs are evident in the tourism and leisure industries.

As presented in Table 2, previous studies primarily used quantitative approaches, analyzing data using structural equation modeling to explore the adoption of AR. So far, only Rauschnabel (2018) and Kalantari and Rauschnabel (2018) have focused on the adoption of ARSG, although in different contexts (including a study on students). A lack of focus on the leisure industry is apparent. In addition, these researchers' approaches have been quantitative or even theoretical, without considering people's views with regard to adoption behavior. Consequently, our study adds to the currently-limited knowledge of ARSG adoption in the cultural tourism industry by using a qualitative approach that aims to assess context-specific variables.

\section{Methods}

\section{Context of study}

The study was conducted at an art gallery in the UK as part of a project exploring the implementation of ARSG in the cultural tourism industry. The gallery is particularly known for $19^{\text {th }}$-century paintings, attracting over half a million visitors each year. The project sought to enhance visitor experience by providing access to information about paintings through ARSG. To do this, a prototype application was developed for this study, augmenting additional information on specific, pre-selected paintings in the art gallery. Participants were able to interact with the application, obtain information from the ARSG in their direct field of vision, and thus learn more about the painting in question. The application consisted of ARSG cards containing basic text information and audiovisual information, which were superimposed onto the gallery paintings. These cards contained information on artists, the paintings, navigation, and a menu with sharing functions. Cards were digitally overlaid into visitors' direct field of vision. 


\section{Data collection}

This study adopted a qualitative approach. Purposive sampling was used until it was determined that data saturation had been reached. 28 visitors to a UK art gallery were selected; half of the sample was recruited on-site on the research day, while the other half was recruited through the art gallery, using the gallery's social media accounts and website to communicate and book a time slot to participate in the study. This sampling method was considered to cover a spectrum of participants, ranging from pre-planned visits to ad hoc visitors to the art gallery. Participants were selected and approached based on demographics in order to reach a diverse range of visitors to the art gallery, from teenagers to retirees. Table 3 provides an overview of study participants.

Participants experienced the art gallery using an ARSG application, which provided overlaid content about paintings, artists, and related paintings, as well as a museum map (see Figure 1). Just before starting the experiment, participants were introduced to the ARSG in order to

Table 3. Profile of study participants.

\begin{tabular}{llc}
\hline Participant & Gender & Age \\
\hline P1 & Male & $30-39$ \\
P2 & Female & Over 60 \\
P3 & Female & Below 20 \\
P4 & Male & $20-29$ \\
P5 & Male & $20-29$ \\
P6 & Male & $40-49$ \\
P7 & Female & $20-29$ \\
P8 & Female & Over 60 \\
P9 & Male & Below 20 \\
P10 & Female & $20-29$ \\
P11 & Female & Below 20 \\
P12 & Female & Below 20 \\
P13 & Male & $50-59$ \\
P14 & Female & $20-29$ \\
P15 & Male & $20-29$ \\
P16 & Female & $20-29$ \\
P17 & Male & $40-49$ \\
P18 & Male & $30-39$ \\
P19 & Male & $30-39$ \\
P20 & Female & $30-39$ \\
P21 & Female & $30-39$ \\
P22 & Male & $20-29$ \\
P23 & Male & $20-29$ \\
P24 & Male & $20-29$ \\
P25 & Male & $30-39$ \\
P26 & Female & $20-29$ \\
P27 & Female & $50-59$ \\
P28 & Female & and above \\
\hline & &
\end{tabular}

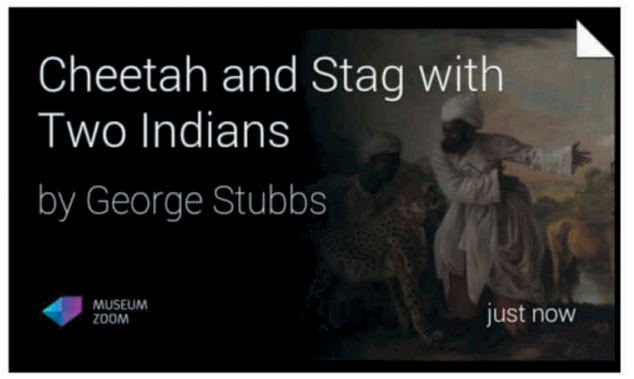

George Stubbs

Born: August 25, 1724, Engla

United Kingdom

Died: July 10, 1806, England, United

Kingdom

$4{ }_{200 M}^{\text {Mussum }}$

just no

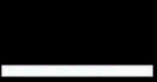

Figure 1. ARSG application demonstrator. 
familiarize them with the device and how to interact with it. After the short demonstration, participants were given a few minutes to test the device themselves before the actual study was conducted. During the experiment, participants could retrieve the digitally-overlaid content on paintings throughout the art gallery by interacting with the device, whereby they could access information on the artist, related paintings, and navigation, as well as a sharing function. After completing the visit, participants took part in a semi-structured interview to share their perceptions and willingness to use this new way of experiencing art galleries.

\section{Data analysis}

Data were analyzed using thematic analysis to identify and contrast themes. This is a flexible approach to comparable analysis methods, as it can be either data- or theory-driven. In the present study, we chose a theory-driven approach, using previous technology adoption theories and contrasting their pre-determined themes with new sub-themes identified in this study.

\section{Findings}

\section{Perceived attributes of innovation}

The present study explored a number of perceived attributes of innovation, which will be laid out and discussed below.

\section{Personal innovativeness}

Self-assessing their own attitudes towards new technology, most participants felt moderately innovative. However, most participants were excited about the novel technology, claiming 'it's something new [and] something fresh' (P3). The hardware was considered 'a completely different way of interacting with someone [and] a completely different way of doing something' (P24).

Participants perceived the technology as still in a development stage, due to occasional errors during the trial. Particularly for participants that were familiar with ARSG from advertisements, it [was] slightly different to the ultimate expectation that [the participant] [had] in terms of having a truly augmented reality' (P17). This seemed to be a primary issue for technology adoption, as P21 mentioned,

'I probably wouldn't do it outside initially, unless it was properly up and running with internet straight away and there were no glitches.'

This attitude of visitors seems to suggest that implementing ARSG to make an impact on a leisure experience requires mature technology, and this attitude should be kept in mind when introducing prototype or beta versions of applications. Despite the possibility to market oneself as a 'front-runner of innovation' or a 'leader in emerging technological solutions', it is risky to prematurely introduce technology that could negatively impact the leisure experience.

\section{Interaction}

Participants felt that interacting with wearable devices was difficult, as people were not accustomed to vibrations being used to emit sound or using voice commands and swiping. An introduction on how to interact with the application, as during the trial, was recommended (P1, P6, P7). Some participants remarked that it did not feel natural to interact with the application, which affected the overall art gallery experience (P1, P4). P16 argued, 'At the beginning it is a little bit difficult to get used to, but after that I felt comfortable with the glass,' suggesting that art gallery visitors could eventually get used to the unfamiliar positioning of the prism for accessing information in the art gallery.

However, opinions regarding the interaction with the software and hardware were twofold. Some participants argued that interaction was very simple, since communicating with the device was limited to tapping, swiping, and voice command (P3, P21, P26). Visitors did not seem familiar with 
the functions of wearable devices, which adds another dimension of complexity to the experience in museum environments. In the leisure industry, the potential drawback of having to learn how to interact with new devices does not seem to be detrimental, as people were generally laid-back attitude and had the time to try out and learn new things.

\section{Obtrusiveness}

P5 outlined that 'it didn't feel too different' to regular glasses, which people already wear and are familiar with, and therefore it was 'less intrusive'. Unobtrusiveness of the wearable device was compared to the feeling of regular glasses, and wearing comfort was assessed by the weight and the visibility to other visitors.

'So if, and when it gets to the point where it is something that's a bit less intrusive in terms of the bulk and the weight of the thing, then I think that it might be an interesting device to have.' (P6)

While some participants reacted positively to the augmented information, others argued that it was distracting, interfering 'with [the visitor's] peripheral vision and field of view' (P6). Since art galleries are highly visual places, this is an important issue that could interrupt the leisure experience. Participants found the Google Glass prism inconvenient, as it was located at the top of the right eye (P9). This was perceived to be 'quite distracting actually, because you are focusing more on the screen, the little screen, than actually looking at the painting' (P4). P7 added in this regard that 'it almost seemed like a little strain on the eye, [...] because it wasn't straight in view.'

In contrast, P6 highlighted the advantage of ARSG being able to provide an 'uninterrupted experience' where visitors could immediately take a picture or access more information without having to take out a phone or camera. This was supported by P11, who stated that 'you don't have to position the camera, it is just right there.' If these arguments are considered for the leisure experience, it seems that personal preferences depend on whether AR - and ARSG particularly - positively or negatively influence the leisure experience.

\section{Visitor benefits}

With regards to visitor benefits, this study found two sub-themes: perceived enjoyment and perceived usefulness. A distinction was made between the beneficial activity (perceived enjoyment) and the beneficial outcome (perceived usefulness). Perceived enjoyment indicated the act of interacting with the ARSG, while perceived usefulness indicated the outcome, such as having learned something from the retrieved information. Since lifelong learning initiatives through visits to art galleries and museums are increasingly important, these results are very relevant to the leisure experience (Tom Dieck, Jung, \& Tom Dieck, 2018).

\section{Perceived enjoyment}

Factors relating to hedonic values seem to be particularly applicable to using ARSG in a leisure context. Participants felt that the experience was more enjoyable if additional information was provided in non-traditional forms, as it was perceived to be an 'exciting' (P13, P27, P28) and 'different' (P20) element of the art gallery visit. All participants agreed that the technology could possibly enhance museum and art gallery visits. Many participants claimed that visitors would be inclined to use ARSG, as it was perceived to be 'fun and different' (P8). This could potentially modify behavior during the visit, as it would 'encourage people to find out more about the art' (P12). Particularly in the leisure industry, perceived enjoyment can be regarded as a key variable of leisure experiences, and the use of ARSG to enhance the experience could be crucial.

\section{Perceived usefulness}

Participants generally maintained that ARSG technology would enhance the museum and art gallery experience by providing access information in a 'natural way' (P1, P23). The possibility to have the 'freedom of choice' (P26) was pointed out, as visitors could choose certain paintings to access 
additional information or simply enjoy the visit by strolling through the gallery (P8, P9). Accessing personalized information was seen as restricting information overload, which P26 described as the 'freedom of choice to look at what you want and especially not having to go on guided tours, you can create your own experience'. Being able to navigate through the art gallery was repeatedly mentioned as helping visitors get around (P14: 'how you want to view the gallery tour thematically, not just by date'). Participants recommended adding a map of the art gallery to the application, which would assist visitors in pinpointing their location in the gallery by '[clicking] on the map and see where you are' (P14) and directing them to the next point of interest (P15).

Participants were also looking for post-experience benefits, such as 'record [and] show it to your friends' (P3), 'share' (P25), or 'take a little clip [to] remember a picture' (P4). The application also inspired participants to actively look for other works of a certain painter, era, or painting style (P20, P23). For some participants, it was difficult to imagine using ARSG in other contexts of their lives, which limited the perceived benefit. For example, P9 claimed that at this point, the immediate benefit was not evident, and compared the device to the current level of widely-used smartphones. The issue of using ARSG in more than one context is an interesting requirement for value creation in the leisure industry. It seems that visitors expected to be able to use ARSG for more than one leisure experience, looking for increased potential benefits to using the technology.

\section{Visitor resistance}

In order to investigate factors for adoption of new technologies, it was not only imperative to study visitor benefits, but also factors that were obstacles to visitors meaningfully utilizing new devices and applications for tourism and leisure purposes. Three key themes were identified: privacy, risk of use, and cost.

\section{Privacy}

As for risks related to privacy concerns, P6 stated not being 'bothered' by it, assuming that companies such as Google already have regular access to private data from various sources. P15 shared the sentiment, stating, 'I probably wouldn't use it to share information particularly, I would use it to find out information myself. So I am not too bothered.' Participants like P19 acknowledged that society is moving in a direction of sharing information, and it eventually needs to accept new privacy standards in every aspect of life, saying, 'I think that is where we are going anyway, and people will get used to it.'

Participants were more concerned about interacting with and adopting the technology, with P12 stating, 'We got used to phones and computer screens and stuff, so I guess we can get used to Google Glass.' Similarly, P13 reasoned, 'The fact that you are using one eye for it and one eye for other things, getting used to it, I suppose that will come.' Overall, limited research has focused on the effects of ARSG and the associated privacy concerns, especially within the leisure industry; it is an important and inevitable issue, as people are using their technologies while they are out in public, risking being filmed or recorded during their daily activities.

\section{Risk of use}

While perceived risk was mostly understood in relation to information quality and negative impact through technological issues, P3 shared being more concerned about the biological effect, with possible results of 'pain in [the] head' or the strain on a person's eyes when using ARSG for longer time periods.

'It takes three hours to walk all around the building. What will be the possible effects after three hours to my eye, for example?' (P3)

Another concern was pointed out by $\mathrm{P} 9$, who shared that people might get 'too distracted and walk into each other, because I found that unless I looked down, I wasn't looking, as I was concentrating on it too much.' P10 held a positive view of the device but still addressed the same issue. 
'I just think some people may not be able to concentrate on where they are going or what they are looking at.' (P10)

\section{Cost}

The high price of wearable devices was one of the reasons that could prevent the application from being used in the future. It was argued that people 'couldn't really justify spending $\$ 1500$ or whatever it costs to get a developer kit' (P6). While P4 would purchase the device 'if it became affordable', participants were unclear about the benefits for daily activities. However, interviewees looked forward to implementations in other areas outside the art gallery, to 'see other benefits other than the museum' (P10), which could potentially justify the purchase (P22).

If art galleries and museums lend devices to visitors, participants confirmed that it would add value to their experience and could potentially become a selling point for the site (P15). P3 shared, 'if an art gallery offered glass, [P3] would always definitely go there compared to another one' (P3). Similarly, P24 suggested the technology would influence 'getting people coming to art galleries more often'. However, participants revealed that it would be less attractive if the art gallery charged for its use.

\section{Societal impact}

\section{Social acceptability}

One of the key issues in using ARSG in public spaces was identified as social barriers, not only in terms of fashion statements, but also as perceived disturbances to people in the immediate vicinity. Many interviewees were concerned with the impact on their immediate surroundings. While P8 and P18 said that ARSG seemed to be 'unobtrusive' to other visitors, P17 and P21 argued that it could negatively impact other visitors when people were constantly verbally interacting with the device in an art gallery.

'I think it can enhance the experience if it just gives you that information with only the minimum amount of interaction, without having to tap and speak. That's annoying, that is going to annoy everyone.' (P17)

P3 shared this view, also declaring, 'If I heard that someone was listening it might be disturbing.' P6 argued that use of such devices in art galleries depended largely on 'social acceptability and conceivability' as a primary concern.

\section{Social interaction}

A few participants felt that wearable AR limits social interaction in the art gallery and that this novel technology hinders visitor-to-visitor interaction. For instance, P10 identified 'not discussing it with other people since you are so concentrated on the image' as a potential drawback, while P9 pointed out that using ARSG might decrease the number of social interactions.

'Before when I walked around about half the gallery with my girlfriend we were just enjoying ourselves talking amongst ourselves, but if you had that in your ear, you are sort of in your own world, away from social interactions.' (P9)

P12 shared this view, arguing that while visitors might get to know more about the art itself, social interaction would be limited. Since wearable devices have not yet been introduced to the mass market, P12 is hesitant about using them for leisure purposes, despite having a positive perception about them in general:

'I just think people should interact more than that and having something on your face where you are completely transfixed. [...] I think it is too much technology and it is a bit of a distraction' (P12). 


\section{Discussion}

This study revealed that the adoption of ARSG technology depends in large part on individual differences, innovation characteristics, and the context of implementation, confirming literature findings (Straub, 2009). In this study, the factor of personal innovativeness did not seem to be dominant, as participants who referred to themselves as not being tech-savvy were still open and willing to try new technology. Research must clarify the difference between a 'willingness to try' new technology (Agarwal \& Prasad, 1998) and a 'willingness to adopt' a new technology (Rogers, 1996).

This trend could be interpreted as a change in traveler behavior in current society, as it can be more convenient to try new products during a trip without having to commit financially and emotionally. Such behavior allows for more flexibility and quicker development in tourism and leisure, but it could actually create more challenges to adopting new technology in the leisure industry due to lack of commitment. As a result, investment in new technologies must be carefully managed and curated in order to allow people to make use of the technology and justify investing in it.

As ARSG is increasingly able to process larger amounts of information in a shorter period of time, information overload is a risk that can impact the leisure experience. In our current society, we observe that people increasingly need and expect to instantly access information. Currently, this is largely achieved with smartphones, which allow visitors to instantly navigate to points of interest or retrieve additional information and suggestions about specific attractions and restaurants. However, in order to do so, visitors undergo a short disruption from the visitor experience in order to take out and access their mobile device. Since such information can be projected more readily into the line of sight through ARSG, the question is not how visitors and tourists will be able to access information, but what information will need to be projected at what specific time, to assure a seamless and uninterrupted leisure experience.

In art galleries, it is imperative to provide information that is not readily available in other forms and could possibly personalize the visitor's experience, to increase the relative advantage of using the device. In this regard, 'freedom of choice' was not only relevant to the content but also the pace of accessing information or consuming the experience.

This study revealed that visitors are looking for more and more devices and applications that are used for various leisure activities that can be relevant and useful in daily activities. This indicates a shift of defining leisure experiences and the way to approach designing experiences in themselves. Since visitors are looking for technology that can benefit and be transferred to various contexts, the boundaries between isolated experiences are blurred and the need to bundle leisure experiences involving multiple stakeholders is increased. Although it makes designing and monitoring the visitor experience more complex, we believe that this approach is in demand by visitors and is needed to elevate staging of memorable leisure experiences.

The benefit of new technologies affecting perceived usefulness has largely been indicated in TAM literature and as a relative advantage in IDT, a key attribute affecting the attitude of consumers (Rauschnabel \& Ro, 2016). However, in the context of ARSG, a more dominant factor was the enjoyment that participants experienced while interacting with the ARSG. According to Davis, Bagozzi, and Warshaw (1992), enjoyment is defined as the intrinsic reward of using a technology. In contrast to perceived usefulness, which is based on extrinsic rewards through achieving a goal, perceived enjoyment relates to the act of doing an activity itself. The importance of enjoyment and overall hedonic experiences to adopting AR in the tourism industry has been confirmed by a number of scholars (Haugstvedt \& Krogstie, 2012; Leue, Tom Dieck, \& Jung, 2014). This study confirms Gabbiadini et al.'s (2018) claim that enjoyment is a key variable in the tourism and leisure context.

The variable of enjoyment is particularly dominant in gaming and gamification of content. Although the aspect of gaming with ARSG was not well developed at the time of study, since then a number of applications and studies have explored the use of ARSG for gaming purposes (Chang, Liu, 
Kang, Kao, \& Chang, 2016; Rauschnabel, 2018a; Zikas et al., 2016). A number of ARSG forms (Microsoft HoloLens, Magic Leap One) currently have the capacity to be used for gaming purposes. However, one key resistance factor was the cost of acquiring one of these devices, a factor confirmed in our research findings. Nonetheless, some games are being prototyped, and a trend can be observed that suggests more AR gaming experiences making a debut in the near future. This will profoundly impact leisure experiences and the way ARSG are used, as well as how experiences will be designed to integrate technology with content. As mentioned above, this could shift visitor expectations and the way leisure experiences will be designed in the future.

An additional attribute that largely impacts the overall adoption of ARSG devices was the costto-value perception. While perceived value and benefit for visitors is one of the key attributes for adopting new technology, we found that the intention to use AR is determined by its cost of use. Tom Dieck and Jung (2018) revealed that high costs of new technology negatively impact adoption, as limited applicability and benefit in other contexts were evident. Participants indicated that the value of implementing ARSG in cultural tourism was still too limited, although they suggested that the perception of cost would decrease with an increase in benefits. In the meantime, a search for alternative methods was suggested in order to drive awareness, familiarity with new technology, and mass adoption. This could be realized by tourist sites offering ARSG in addition to or instead of audio guides, as indicated by Han et al. (2013).

However, this development raises the question of whether such differentiated experiences are desired by tourist sites. Researchers and industry experts need to consider that more integration of AR in sites such as museums could alter the core product and might distract from engaging with the actual product. However, it could also provide the possibility to re-interpret art and re-tell stories from different perspectives, offering new and more personalized ways of experiencing the tourist site, possibly spurring repeated visits. Close cooperation with museum curators will be essential. It is evident that ARSG in cultural tourism and in the wider leisure industry should not only be considered for projecting already-existing information but also for focusing on offering added value to the visitor. It is imperative that the visitor is at the center of the design stage of ARSG applications, in order to identify value-adding elements that can only be offered through ARSG.

Participants largely shared the opinion that art galleries provide a quiet and peaceful environment. This provoked two areas of thought in this study. On the one hand, it raised the question of whether the art gallery experience could be enhanced by ARSG by focusing on hedonic values, making the experience different, more enjoyable, and able to attract people to visit the site, as suggested in TAM literature (Haugstvedt \& Krogstie, 2012; Leue et al., 2014). On the other hand, it provoked conflict related to social elements using voice-driven technology in art galleries. Participants were concerned about interacting with the device by voice-command, disturbing other visitors in the immediate surroundings. This could potentially limit technology implementation in various environments, such as museums, churches, and other sacred places. Contrary to the social construct identified in UTAUT - where social influence means that people in the close social circle recommend the use of new technology - the findings in this study suggest that visitors are mostly concerned with losing the social element by using ARSG. This occurred because participants anticipated that art gallery visitors would largely focus on the information displayed on the device rather than discuss the art with others.

In our study, the degree of mass adoption was not found to be limited to the visitor's/user's perspective, as in the original TAM and DIT, but was driven by wider society. This study revealed that societal impact was a strong concern for participants, suggesting that introducing new technology needs to take into account the environment of implementation. When focus is trained solely on the visitor and the interaction with the new technology at the cultural tourist attraction, limited attention is given to the environment and the augmented scenario. As a result, we have a narrow understanding of the impact the technology will have on the wider society that influences the behavior and decisionmaking process of visitors. 
Yang (2007) revealed that consumer attitudes towards mobile advertising are strongly influenced by social norms. This was confirmed by Chong, Chan, and Ooi (2012) in their study combining constructs from TAM and IDT, who declared that social influence - through trends, mass media, and peers - was one of the key predictors of consumers' decision to adopt m-commerce services. Consequently, including societal impact as an independent variable in our ARSG adoption model can be considered one of this study's key contributions to existing adoption theories. Previous models considered social influences to be on the same level with benefits and perceptions (Kalantari \& Rauschnabel, 2018); however, our study has shown that societal impact is an overarching theme in the ARSG art gallery context, which might be linked to the traditionally-conservative nature of visiting art galleries. Thus, public perception plays an important role for visitors.

\section{Conclusion}

The aim of this paper was to explore factors influencing ARSG adoption in a cultural tourism context, leaning on prior theories in consumer adoption of new technology. As a result, we propose the following model to spell out factors of adoption (Figure 2).

\section{Theoretical contributions}

This study adds to the academic body of knowledge in adoption theory by exploring technological characteristics, the impact of human-computer interaction, and the adoption of ARSG in the cultural tourism industry. Previous research (Tom Dieck \& Jung, 2018) revealed that it is crucial to explore context-specific factors to increase technology-adoption success. This study explored a number of theories and related factors to provide a comprehensive framework of ARSG adoption in the tourism and leisure industries. It adds to existing TAM, IDT, TPB, and TRA

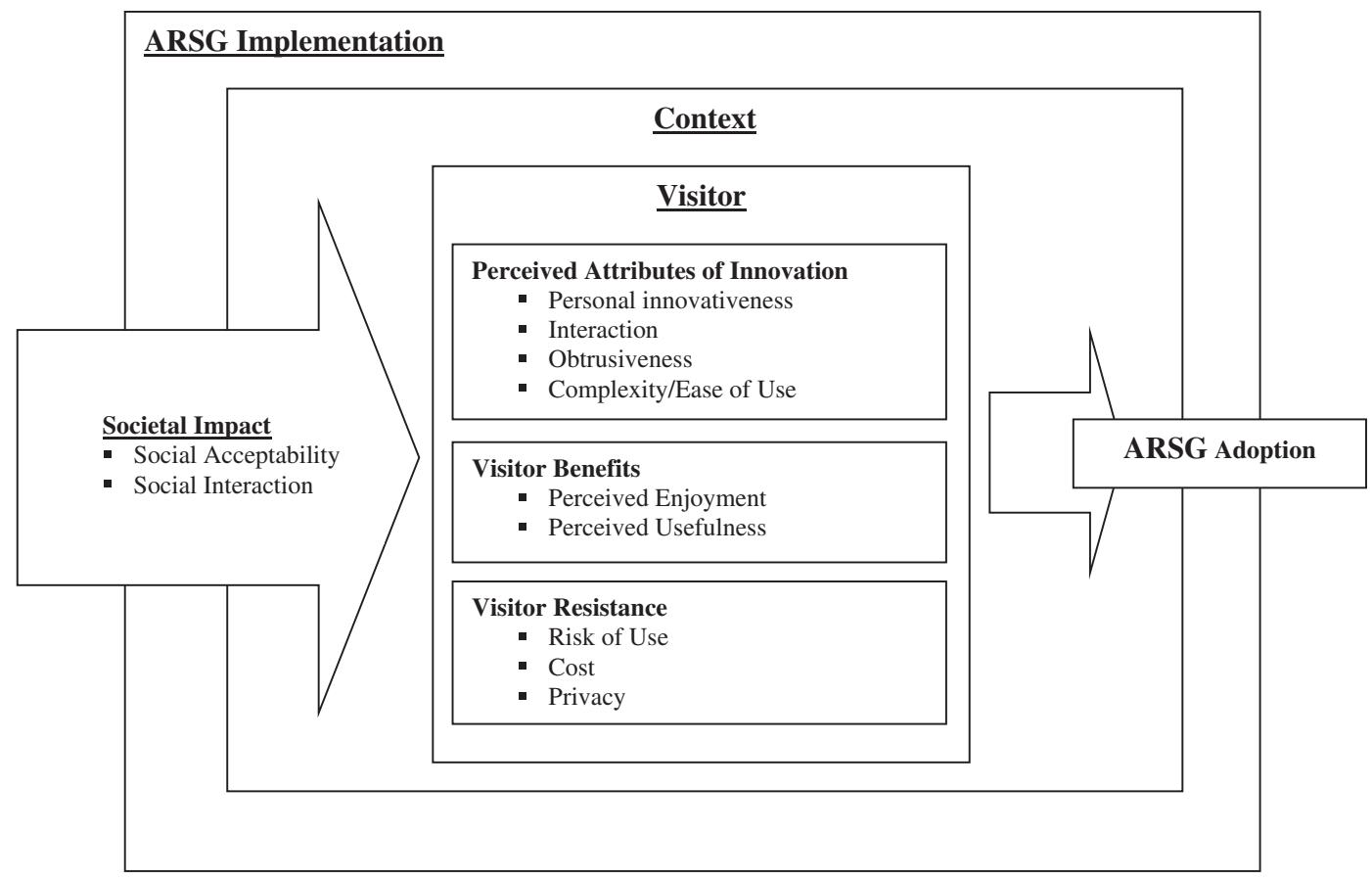

Figure 2. Augmented Reality Smart Glasses (ARSG) visitor adoption model. 
research by extending and applying the theory to a new technology-related tourism context. This study demonstrates that, for an industry that is largely interconnected and often blends with the work environment and societal values, it is not sufficient to look at adoption theories in isolation; instead, a holistic approach must be taken to studying the adoption of emerging technology.

The assumption held in this paper is the notion that when research explores technology adoption in today's environment, it is insufficient to explore drivers on individual level and disregard how these are perceived on a social level and are interconnected to the wider macro environment. It is also not reasonable to consider only the macro environmental factors by investigating societal factors and ignoring perceptions of individual visitors, particularly in a time where personalization is becoming the norm. Therefore, the study identifies adoption factors that should be considered when implementing wearable devices in the cultural tourism context, combining constructs from IDT, TAM, and TRA. This study reveals that social norms, including social acceptability and social interaction, are of great concern for tourists using technology around peers.

This social acceptability element - in terms of the acceptability of using wearables in public was previously picked up by a number of studies. For instance, Tom Dieck et al. (2016) found a resistance by some people to walk around with ARSGs, due to the fact that it attracts a lot of (often negative) attention. Chuah et al. (2016) also called for further research into the public's resistance to using wearable technology. While tourists are divided between embracing innovative design and preferring familiar design options, it is evident that all tourists are conscious of the impact of technology use on the experience of their peers.

\section{Managerial implications}

While it is clear that tourism experience providers are primarily concerned with the immediate environment and context, this study suggests that industry professionals need to take a more holistic approach when implementing ARSG. The findings show that social acceptability is a crucial factor, as visitors were rather self-conscious about clearly-visible technology and were concerned about disrupting other visitors by interacting with the technology. The findings of this study not only apply to the cultural tourism industry but also propose an ARSG adoption model that can be applied across cultural tourism destinations and the wider leisure industry. The study shows that the adoption of ARSG in cultural tourism depends in large part on its perceived value and its relation to visitors' resistance factors, including cost. In particular, the value to visitors needs to be clearly understood to ensure successful implementation of ARSG and similar wearable devices.

\section{Limitations and future research}

As in every study, limitations in research design and data collection need to be acknowledged. Since the research was held in a closed, controlled environment, it is uncertain how tourists would experience the use of ARSG in other cultural tourism settings. Findings of this research may not be generalizable, due to the nature of qualitative research; however, this research is unique in terms of generating a deeper understanding of visitors' adoption of ARSG applications in the cultural tourism and leisure industries, which has the potential to change leisure experiences and practices in the future.

Further research can expand the focus to a different or much wider leisure/tourism context, and more in-depth investigation can be conducted on how ARSG specifically influences leisure/tourism experiences and practices. In addition, a quantitative study in a similar context is recommended, to confirm the study outcomes. Future studies are recommended in other cultural tourism settings, to explore how tourists perceive ARSG in other contexts and to draw generalizable conclusions. Further empirical research, particularly of a qualitative nature, should be conducted to extend and validate the model. ARSG are becoming increasingly important; therefore, academia and the tourism and leisure 
industries need to consider how this emerging technology adds value to the tourism experience. Understanding the key factors of adoption of ARSG is crucial to ensuring its successful implementation in cultural tourism and the wider leisure environment.

\section{Acknowledgments}

This work was supported by Knowledge Exchange Innovation Fund (M-80024.8.6) by Manchester Metropolitan University.

Authors would like to thank Manchester Art Gallery and 33Labs for their co-operation in this project.

\section{Disclosure statement}

No potential conflict of interest was reported by the authors.

\section{Funding}

This work was supported by the Manchester Metropolitan University [M-80024.8.6].

\section{Notes on contributors}

Dai-In Danny Han is a senior lecturer in Marketing and Sustainable Strategic Business Design and a researcher in AR/VR user experience design at Breda University of Applied Sciences. His research primarily focuses on the design of AR and VR enhanced experiences and the impact on consumer psychology and behaviour.

M. Claudia tom Dieck is a part of the Augmented and Virtual Reality Hub at Manchester Metropolitan University. Claudia received her $\mathrm{PhD}$ on digital tourism at Manchester Metropolitan University and her research interest range from social media and customer relationship management to augmented reality and cultural heritage tourism.

Timothy Jung is the Director of Creative AR \& VR Hub, at Manchester Metropolitan University, UK. He has been involved in a number of funded AR \& VR research projects at national and international level. His research focuses on the application of AR, VR, and multi-sensory visitor experiences.

\section{References}

Agarwal, R., \& Prasad, J. (1998). A conceptual and operational definition of personal innovativeness in the domain of information technology. Information Systems Research, 9, 204-215.

Ajzen, I. (1985). From intentions to actions: A theory of planned behavior. In J. Kuhl \& J. Beckmann (eds.), Action control (pp. 11-39). Berlin, Heidelberg: Springer.

Ajzen, I., \& Fishbein, M. (1975). A Bayesian analysis of attribution processes. Psychological Bulletin, 82(2), 261.

Amaro, S., \& Duarte, P. (2015). An integrative model of consumers' intentions to purchase travel online. Tourism Management, 46, 64-79.

Chang, Y. J., Liu, H. H., Kang, Y. S., Kao, C. C., \& Chang, Y. S. (2016). Using augmented reality smart glasses to design games for cognitive training. In Proceedings of 2016 13th International Conference on Remote Engineering and Virtual Instrumentation (REV) (pp. 252-253). New York: IEEE.

Chong, A. Y. L., Chan, F. T., \& Ooi, K. B. (2012). Predicting consumer decisions to adopt mobile commerce: Cross country empirical examination between China and Malaysia. Decision Support Systems, 53, 34-43.

Chuah, S. H. W., Rauschnabel, P. A., Krey, N., Nguyen, B., Ramayah, T., \& Lade, S. (2016). Wearable technologies: The role of usefulness and visibility in smartwatch adoption. Computers in Human Behavior, 65, 276-284.

Chung, N., Lee, H., Kim, J. Y., \& Koo, C. (2018). The role of augmented reality for experience-influenced environments: The case of cultural heritage tourism in Korea. Journal of Travel Research, 57(5), 627-643.

Davis, F. D. (1989). Perceived usefulness, perceived ease of use, and user acceptance of information technology. MIS Quarterly, 13(3), 319-340.

Davis, F. D., Bagozzi, R. P., \& Warshaw, P. R. (1992). Extrinsic and intrinsic motivation to use computers in the workplace. Journal of Applied Social Psychology, 22(14), 1111-1132.

Foley, M., \& McPherson, G. (2000). Museums as leisure. International Journal of Heritage Studies, 6(2), 161-174.

Gabbiadini, A., Sagioglou, C., \& Greitemeyer, T. (2018). Does Pokémon Go lead to a more physically active life style? Computers in Human Behavior, 84, 258-263. 
Han, D., Jung, T., \& Tom Dieck, M. C. (2019). Translating tourist requirements into mobile AR application engineering through QFD. International Journal of Human-Computer Interaction.

Han, D. I., Jung, T., \& Gibson, A. (2013). Dublin AR: Implementing augmented reality in tourism. In Z. Xiang \& I. Tussyadiah (eds.), Information and communication technologies in tourism 2014 (pp. 511-523). Cham: Springer.

Han, D. I., Tom Dieck, M. C., \& Jung, T. (2017). User experience model for augmented reality applications in urban heritage tourism. Journal of Heritage Tourism, 1-16. doi:10.1080/1743873X.2016.1251931

Haugstvedt, A. C., \& Krogstie, J. (2012). Mobile augmented reality for cultural heritage: A technology acceptance study. In 2012 IEEE International Symposium on Mixed and Augmented Reality (ISMAR), Atlanta, USA, 247-255. IEEE.

Hein, D. W., Jodoin, J. L., Rauschnabel, P. A., \& Ivens, B. S. (2018). Are wearables good or bad for society?: An exploration of societal benefits, risks, and consequences of augmented reality smart glasses. In Wearable technologies: Concepts, methodologies, tools, and applications (pp. 1313-1337). Hershey, USA: IGI Global.

Jhajharia, S., Pal, S. K., \& Verma, S. (2014). Wearable computing and its application. International Journal of Computer Science and Information Technologies, 5(4), 5700-5704.

Jung, T., Chung, N., \& Leue, M. C. (2015). The determinants of recommendations to use augmented reality technologies: The case of a Korean theme park. Tourism Management, 49, 75-86.

Jung, T., Tom Dieck, M. C., Lee, H., \& Chung, N. (2016). Effects of virtual reality and augmented reality on visitor experiences in museum. In A. Inversini \& R. Schegg (eds.), Information and communication technologies in tourism 2016 (pp. 621-635). Cham: Springer.

Jung, T., Tom Dieck, M. C., Moorhouse, N., \& Tom Dieck, D. (2017). Tourists‘ experience of virtual reality applications. In 2017 IEEE International Conference on Consumer Electronics (ICCE), Las Vegas, USA, $208-210$.

Jung, T. H., Lee, H., Chung, N., \& Tom Dieck, M. C. (2018). Cross-cultural differences in adopting mobile augmented reality at cultural heritage tourism sites. International Journal of Contemporary Hospitality Management, 30(3), 1621-1645.

Jung, T. H., \& Tom Dieck, M. C. (2017). Augmented reality, virtual reality and 3D printing for the co-creation of value for the visitor experience at cultural heritage places. Journal of Place Management and Development, 10(2), 140-151.

Kalantari, M., \& Rauschnabel, P. (2018). Exploring the early adopters of augmented reality smart glasses: The case of Microsoft HoloLens. In T. Jung \& M. C. tom Dieck (eds.), Augmented reality and virtual reality (pp. 229-245). Cham: Springer.

Kourouthanassis, P., Boletsis, C., Bardaki, C., \& Chasanidou, D. (2015). Tourists responses to mobile augmented reality travel guides: The role of emotions on adoption behavior. Pervasive and Mobile Computing, 18, 71-87. doi:10.1016/j.pmcj.2014.08.009

Layland, E. K., Stone, G. A., Mueller, J. T., \& Hodge, C. J. (2018). Injustice in mobile leisure: A conceptual exploration of pokémon go. Leisure Sciences, 40(4), 288-306. doi:10.1080/01490400.2018.1426064

Leue, M. C., Jung, T., \& Tom Dieck, D. (2015). Google glass augmented reality: Generic learning outcomes for art galleries. In I. Tussyadiah \& A. Inversini (eds.), Information and communication technologies in tourism 2015 (pp. 463-476). Cham: Springer.

Leue, M. C., Tom Dieck, D., \& Jung, T. (2014). A theoretical model of augmented reality acceptance. e-Review of Tourism Research, 5, 1-5.

Mathieson, K. (1991). Predicting user intentions: Comparing the technology acceptance model with the theory of planned behavior. Information Systems Research, 2(3), 173-191. doi:10.1287/isre.2.3.173

Rauschnabel, P. A. (2018). Virtually enhancing the real world with holograms: An exploration of expected gratifications of using augmented reality smart glasses. Psychology \& Marketing, 35(8), 557-572.

Rauschnabel, P. A. (2018a). A conceptual uses \& gratification framework on the use of augmented reality smart glasses. In T. Jung \& M. C. tom Dieck (eds.), Augmented reality and virtual reality (pp. 211-227). Cham: Springer.

Rauschnabel, P. A., \& Ro, Y. K. (2016). Augmented reality smart glasses: An investigation of technology acceptance drivers. International Journal of Technology Marketing, 11(2), 123-148.

Rogers, E. M. (1996). Diffusion of innovations (4th ed.). New York: Free Press.

Schultz, C. S., \& McKeown, J. K. (2018). Introduction to the special issue: Toward "Digital Leisure Studies". Leisure Sciences, 40(4), 223-238.

Straub, E. T. (2009). Understanding technology adoption: Theory and future directions for informal learning. Review of Educational Research, 79(2), 625-649.

Sultan, N. (2015). Reflective thoughts on the potential and challenges of wearable technology for healthcare provision and medical education. International Journal of Information Management, 35(5), 521-526.

Tom Dieck, M. C., Fountoulaki, P., \& Jung, T. H. (2018a). Tourism distribution channels in European island destinations. International Journal of Contemporary Hospitality Management, 30(1), 326-342.

Tom Dieck, M. C., \& Jung, T. (2018). A theoretical model of mobile augmented reality acceptance in urban heritage tourism. Current Issues in Tourism, 21(2), 154-174. 
Tom Dieck, M. C., Jung, T., \& Han, D. I. (2016). Mapping requirements for the wearable smart glasses augmented reality museum application. Journal of Hospitality and Tourism Technology, 7(3), 230-253.

Tom Dieck, M. C., Jung, T. H., \& Rauschnabel, P. A. (2018b). Determining visitor engagement through augmented reality at science festivals: An experience economy perspective. Computers in Human Behavior, 82, 44-53.

Tom Dieck, M. C., Jung, T. H., \& Tom Dieck, D. (2018). Enhancing art gallery visitors' learning experience using wearable augmented reality: Generic learning outcomes perspective. Current Issues in Tourism, 21(17), 2014-2034.

Venkatesh, V., \& Bala, H. (2008). Technology acceptance model 3 and a research agenda on interventions. Decision Sciences, 39(2), 273-315.

Venkatesh, V., \& Davis, F. D. (2000). A theoretical extension of the technology acceptance model: four longitudinal field studies. Management Science, 46(2), 186-204. doi:10.1287/mnsc.46.2.186.11926

Venkatesh, V., Morris, M. G., Davis, G. B., \& Davis, F. D. (2003). User acceptance of information technology: Toward a unified view. MIS Quarterly, 27(3), 425-478.

Yang, K. C. (2007). Exploring factors affecting consumer intention to use mobile advertising in Taiwan. Journal of International Consumer Marketing, 20(1), 33-49.

Zikas, P., Bachlitzanakis, V., Papaefthymiou, M., Kateros, S., Georgiou, S., Lydatakis, N., \& Papagiannakis, G. (2016). Mixed reality serious games and gamification for smart education. European Conference on Games Based Learning, Steinkjer, Norway, 805. 